\title{
Intraoral scanning reduces procedure time and improves patient comfort in fixed prosthodontics and implant dentistry: a systematic review
}

\author{
Rafael Siqueira ${ }^{1}$ Matthew Galli ${ }^{1}$ - Zhaozhao Chen ${ }^{1} \cdot$ Gustavo Mendonça $^{2} \cdot$ Luiz Meirelles $^{3} \cdot$ Hom-Lay Wang $^{1}$. \\ Hsun-Liang Chan ${ }^{1}$
}

Received: 6 November 2020 / Accepted: 21 August 2021 / Published online: 27 September 2021

( ) The Author(s), under exclusive licence to Springer-Verlag GmbH Germany, part of Springer Nature 2021

\begin{abstract}
Objectives The primary aim of this systematic review was to evaluate whether intraoral scanning (IOS) is able to reduce working time and improve patient-reported outcome measures (PROMs) compared to conventional impression (CI) techniques, taking into account the size of the scanned area. The secondary aim was to verify the effectiveness of IOS procedures based on available prosthodontic outcomes.

Materials and methods Electronic and manual literature searches were performed to collect evidence concerning the outcomes of IOS and CI performed during the treatment of partially and complete edentulous patients for tooth- or implantsupported restorations. Qualitative analysis was conducted to evaluate the time efficiency and PROMs produced by the two different techniques. Clinical prosthodontic outcomes were analyzed among the included studies when available.

Results Seventeen studies ( 9 randomized controlled trials and 8 prospective clinical studies) were selected for qualitative synthesis. The 17 included studies provided data from 430 IOS and 370 CI performed in 437 patients. A total of 7 different IOS systems and their various updated versions were used for digital impressions. The results demonstrated that IOS was overall faster than CI independent of whether quadrant or complete-arch scanning was utilized, regardless of the nature of the restoration (tooth or implant supported). IOS was generally preferred over CI regardless of the size of the scanned area and nature of the restoration (tooth- or implant-supported). Similar prosthodontic outcomes were reported for workflows implementing CI and IOS.

Conclusions Within the limitations of this systematic review, IOS is faster than CI, independent of whether a quadrant or complete arch scan is conducted. IOS can improve the patient experience measured by overall preference and comfort and is able to provide reliable prosthodontic outcomes.

Clinical relevance Reduced procedure working time associated with the use of IOS can improve clinical efficiency and the patient experience during impression procedures. Patient-reported outcome measures (PROMs) are an essential component of evidence-based dental practice as they allow the evaluation of therapeutic modalities from the perspective of the patient. IOS is generally preferred by patients over conventional impressions.
\end{abstract}

Keywords Conventional workflow $\cdot$ Digital workflow $\cdot$ Digital impression $\cdot$ Intraoral scanner $\cdot$ Quality of outcomes $\cdot$ Time efficiency

Hsun-Liang Chan

hlchan@umich.edu

Extended author information available on the last page of the article

\section{Introduction}

The process of fabricating a dental prosthesis typically starts with impressions to capture the anatomy of the prepared teeth or location of the endosseous implants, as well as the morphology of the surrounding tissues. This critical step determines the accuracy of the models and ultimately that of the prostheses [1]. For decades, conventional impressions have often used polyvinyl siloxane (PVS) impression 
materials [2, 3]. Major drawbacks of conventional impression techniques include their physical material properties, consistency, taste, and odor, all of which may negatively influence the patient experience [4]. Clinical studies have indicated that conventional impressions are ranked among one of the most unpleasant experiences during fixed [5, 6], removable [5], and implant prosthodontics [7]. Thus, it is desirable to pursue alternative methods to improve patientreported outcomes in prosthetic and implant dentistry.

Digital optical technologies provide clinicians with additional options to optimize workflows while improving the patient experience. Intraoral scanning (IOS) has been advocated as an advantageous alternative to conventional impressions, allowing previsualization of the area of interest in three dimensions [8], reduced working time, and improved patient-reported outcomes [9-16]. IOS is capable of providing accurate digital casts, decreasing the risk of distortion associated with the use of impression materials [17], and also has the potential to optimize workflows due to the ability to quickly rescan a missed area. This is in contrast to conventional impressions where the operator has to repeat the entire procedure if errors are present [15].

Digital data obtained with IOS in combination with computer-aided design (CAD) and computer-aided manufacturing (CAM) allows for a completely digital workflow. Digital prosthetic workflows have been extensively investigated in the context of fixed prosthodontics [18] and implant dentistry [19]. Moreover, it has been suggested that a reduced IOS area, such as a quadrant scan, may provide sufficient information to cover a broad variety of restorative indications, including single crowns and short-span fixed prostheses [20,21]. Quadrant scans are not only time effective but are also less vulnerable to deviations in accuracy compared to complete-arch scanning [22]. Research has shown that the larger the size of the scanned area, the lower the accuracy [23]. The potential for accumulation of errors is higher in complete-arch scans due to numerous factors such as saliva, reflective restorations, movable mucosa, surface characteristics, and different scanning protocols [22, 24-26]. It can also be speculated that complete arch scans are more time consuming and that this could influence patient satisfaction in comparison to quadrant scans.

For many years, the literature on fixed prosthodontics and implant treatment has focused on disease-oriented outcomes, such as numerical replacement of missing teeth in need of restorative work, biologic/prosthetic complications, and survival rates [27]. Patient-reported outcome measures (PROMs) are an essential component of evidence-based dental practice as they allow the evaluation of patient perceptions toward a specific treatment. PROMs have been the focal point of numerous studies that assessed subjective patient satisfaction regarding comfort, speed, and general predilection for conventional and digital impression techniques [9-15, 28, 29]. A previous systematic review [30] explored PROMs and procedure working time for digital versus conventional impressions, but due to limitations in the number of clinical studies available at the time, definitive conclusions could not be reached. In addition, the size of the scanned area (quadrant or complete arch) was not fully explored, which is an important variable to consider when comparing the time effectiveness of IOS and conventional impressions. To the best of our knowledge, there are no previously published systematic reviews evaluating PROMs and time efficiency that compared quadrant- and complete-arch scans to conventional impressions. Thus, the primary aim of this systematic review was to evaluate whether IOS is able to reduce working time and improve PROMs compared to conventional impression techniques, taking into account the size of the scanned area. The secondary aim was to assess the impact of the impression technique on the quality of the work in order to verify the effectiveness of IOS procedures based on available prosthodontic outcomes.

\section{Material and methods}

\section{Study registration}

The protocol of the present article was registered in the PROSPERO database funded by the National Institute for Health Research, University of York, Center for Reviews and Dissemination (www.crd.york.ac.uk/PROSPERO) and allocated the identification number CRD42020187021. The Cochrane Collaboration guidelines were followed during the preparation of this manuscript [31].

\section{Search strategy}

The present systematic review followed the PRISMA guidelines for reporting time efficiency and PROMs in order to compare digital and conventional impressions in partially and completely edentulous patients during treatment for tooth- or implant-supported restorations. The term "conventional impression" was used to define an impression technique that utilized stock or customized trays in conjunction with PVS or polyether impression materials. A "digital impression" was considered a digitalization of the dental arches using an intraoral scanner device. The following PICOS question [32] was formulated to address the specific aim of the study: "Is IOS capable of reducing procedure working time and improving patient satisfaction compared to conventional impressions obtained during prosthetic rehabilitation? 
- Population (P): partially and complete edentulous patients receiving tooth- or implant-supported restorations;

- Intervention (I): digital impression procedure;

- Comparison (C): conventional impression procedure;

- Outcomes $(\mathrm{O})$ : procedure working time and patientreported outcomes;

- Study design (S): randomized clinical trials (RCTs) and prospective clinical studies

Electronic searches were initially performed in three databases (PubMed/MEDLINE, Embase, and Cochrane Central) for articles published up to July 31,2020 . The entire search process was updated on July 25, 2021, and no restrictions were set for the date of publication, journal, or language. The search terms comprising the combination of key words were listed as below:

Pubmed: (conventional impression OR analog impression OR analog technique OR PVS impression OR implant impression) AND (digital impression OR intraoral scanning OR intraoral scanner OR intraoral scan) AND (fixed partial denture[MeSH Terms] OR fixed bridge[MeSH Terms] OR prepared teeth[Title/Abstract] OR single tooth restoration[Title/Abstract] OR single crown[Title/Abstract] OR dental prostheses, implant supported[MeSH Terms] OR implant supported dental prostheses[MeSH Terms] OR dental implant[MeSH Terms] OR implant[Title/Abstract]).

Embase: ("conventional impression" OR (conventional AND impression) OR "analog impression" OR (analog AND impression) OR "analog technique" OR (analog AND ("technique"/exp OR technique)) OR "pvs impression" OR (pvs AND impression)) AND ("implant impression" OR ((“implant"/exp OR implant) AND impression)) AND ("digital impression" OR (digital AND impression) OR "intraoral scanning" OR (intraoral AND scanning) OR "intraoral scanner"/exp OR "intraoral scanner" OR (intraoral AND ("scanner"/exp OR scanner)) OR "intraoral scan" OR (intraoral AND scan)) AND ("fixed partial denture"/exp OR "prepared teeth":ti,ab,kw OR "single tooth restoration":ti,ab,kw OR "single crown":ti,ab,kw OR "implant-supported denture"/ exp OR “tooth implantation"/exp OR “implant”/exp).

Cochrane: (conventional impression OR analog impression OR analog technique OR PVS impression OR implant impression) AND (digital impression OR intraoral scanning OR intraoral scanner OR intraoral scan) AND (fixed partial denture OR fixed bridge OR prepared teeth OR single tooth restoration OR single crown OR dental prostheses, implant-supported OR implant-supported dental prostheses OR dental implant OR implant). In addition, for examining unpublished trials, the grey literature, nonprofit reports, government research, or other materials, were also electronically explored through searching in ClinicalTrials.gov and OpenGrey (www.opengrey.eu).
To ensure a thorough screening process, the electronic search was complemented with a manual search in the following journals: Clinical Implant Dentistry and Related Research, Clinical Oral Implants Research, International Journal of Oral Implantology, The International Journal of Prosthodontics, Journal of Esthetic and Restorative Dentistry, Journal of Prosthodontics, Journal of Prosthetic Dentistry, International Journal of Computerized Dentistry, Implant Dentistry, The International Journal of Oral and Maxillofacial Implants, and The International Journal of Periodontics and Restorative Dentistry. In addition, the snowball sampling approach was performed where reference lists of included manuscripts and the bibliographies of systematic reviews were searched manually.

\section{Study selection}

Two reviewers (R.S. and M.G.) screened all titles and abstracts independently. Full-text evaluation of the remaining publications was performed using the inclusion and exclusion criteria listed below:

Inclusion criteria:

(1) RCTs or nonrandomized prospective clinical studies where a minimum of 10 patients underwent digital and conventional impression procedures;

(2) Studies including patients that received tooth- or implant-supported restorations;

(3) Studies providing a comparison of procedure working time between conventional and digital workflows with defined start and end points;

(4) Studies reporting PROMs;

(5) Studies providing the extent of the scanned area during IOS

\section{Exclusion criteria:}

(1) In vitro or ex vivo studies, reviews, or expert opinions;

(2) Studies not comparing digital and conventional impression techniques;

(3) Studies not reporting the size of the scanned area during digital impression procedures;

(4) Studies where a prosthetic rehabilitation was not performed

\section{Data extraction and statistical analysis}

Two reviewers, R.S. and M.G., independently extracted data from the included studies. Disagreements were resolved through discussion with a third author (Z.C.) for reaching a consensus. Where data was unclear or incomplete, the authors of the publication were contacted for further explanation. Data such as the number of included patients, type of 
restoration, impression method utilized, number of impression procedures performed, size of the scanned area, type of scanner, type of conventional impression material, duration of time recorded for impression procedures, and PROMs were collected and systematically analyzed.

The gathered data from the included clinical trials were planned to be presented descriptively without a statistical comparison among the treatments due to heterogeneity in the chosen start and end points for time measurements, as well as different designs for the questionnaires and scales utilized for PROMs. Procedure working time and PROMs were reported as means with standard deviations utilizing published data from included trials, when available. Mean working times were calculated for digital and conventional impression techniques, subdivided based on the implant or tooth-supported restorative workflows and the size of the scanned area (quadrant or complete arch). The mean values calculated for procedure working time represented the mean of the means. The standard deviations of the reported means from included studies were also calculated. For studies that included multiple IOS systems, the mean working times, retake times, and retake numbers reported in the present review represented a mean of the means of the systems used $[14,33]$. In addition, available direct or indirect quantitative data regarding the quality of the digital impressions were explored based on clinical assessment of crown fit during prosthetic delivery.

\section{Quality assessment}

The risk of bias for the included RCTs was assessed using the Cochrane collaboration tool [31]. Seven criteria were evaluated: random sequence generation, allocation concealment, blinding of participants and personnel, blinding of outcome assessment, incomplete outcome data, selective reporting, and other sources of bias. Each individual criterion was assigned a rating of low, unclear, or high risk of bias. Furthermore, the Newcastle-Ottawa Scale (NOS) was used to evaluate the included non-RCTs [34]. Each included article could attain a maximum of nine stars during the assessment of methodological quality. Studies with 7-9 points were arbitrarily deemed to have had a low risk of bias, with 4-6 points indicating a moderate risk of bias, and fewer than 4 points suggesting a high risk of bias.

\section{Results}

\section{Study selection}

The initial electronic search through PubMed/MEDLINE, Embase, and Cochrane Central for articles yielded 711 articles. An additional six articles were identified with manual searches yielding a total of 717 articles for review. After removing duplicates, 440 papers were available for screening. The abstracts of 86 papers were evaluated after the exclusion of articles by title, and 29 articles were selected for independent full-text reviews by two investigators (R.S. and M.G.). After screening the remaining studies based on the inclusion and exclusion criteria as well as the PICOS question, 12 articles were excluded (Supplementary Table 1), and 17 studies were ultimately selected for qualitative synthesis (Fig. 1). Of these 17 studies, nine were randomized controlled trials (RCTs), and eight were prospective clinical

Fig. 1 PRISMA flowchart

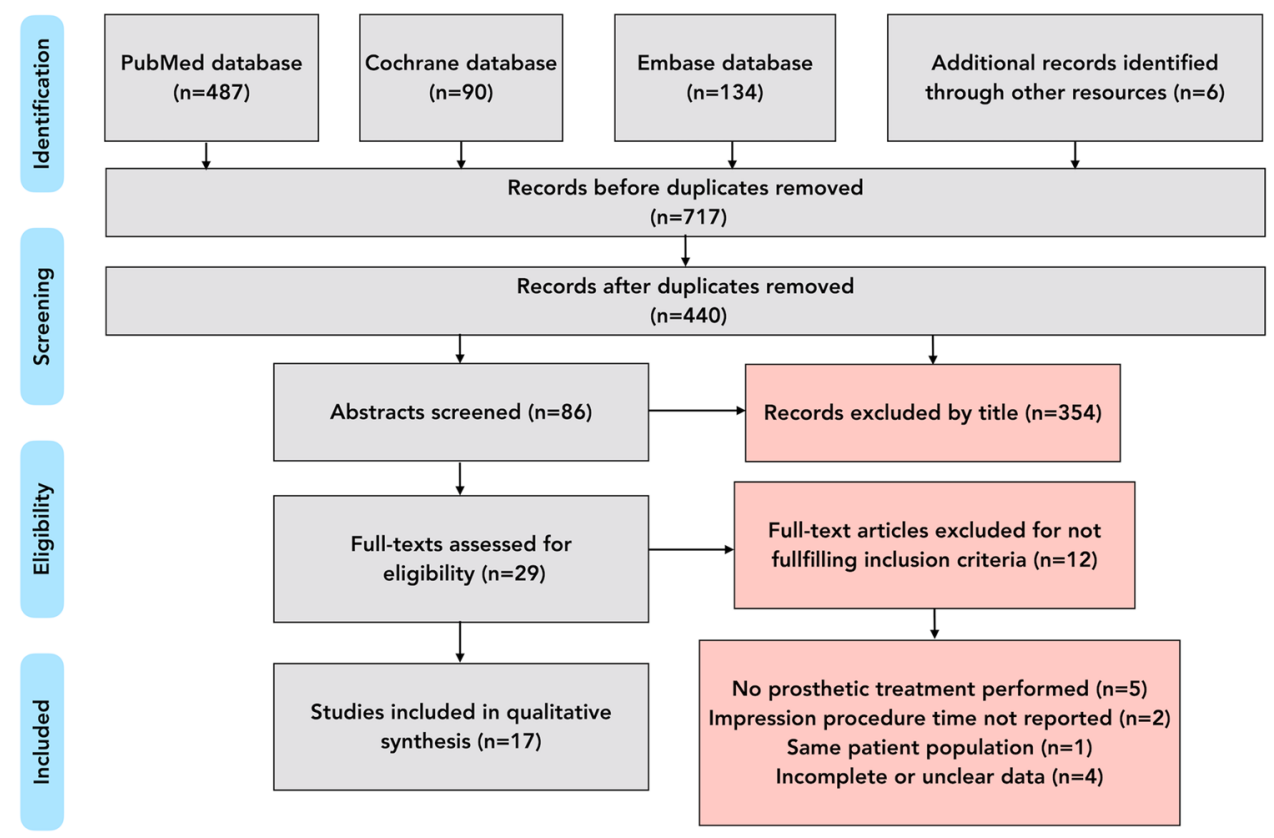




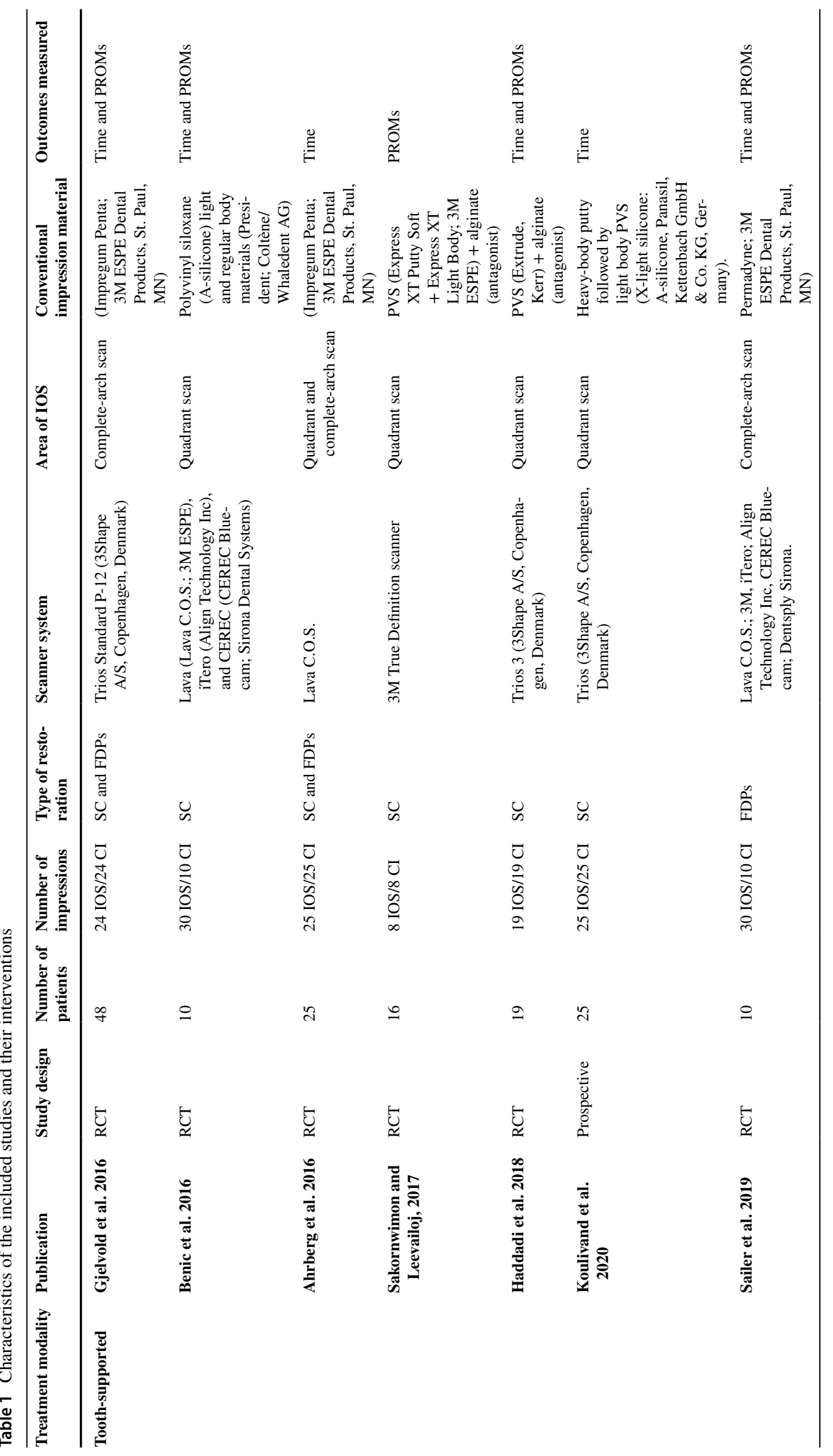




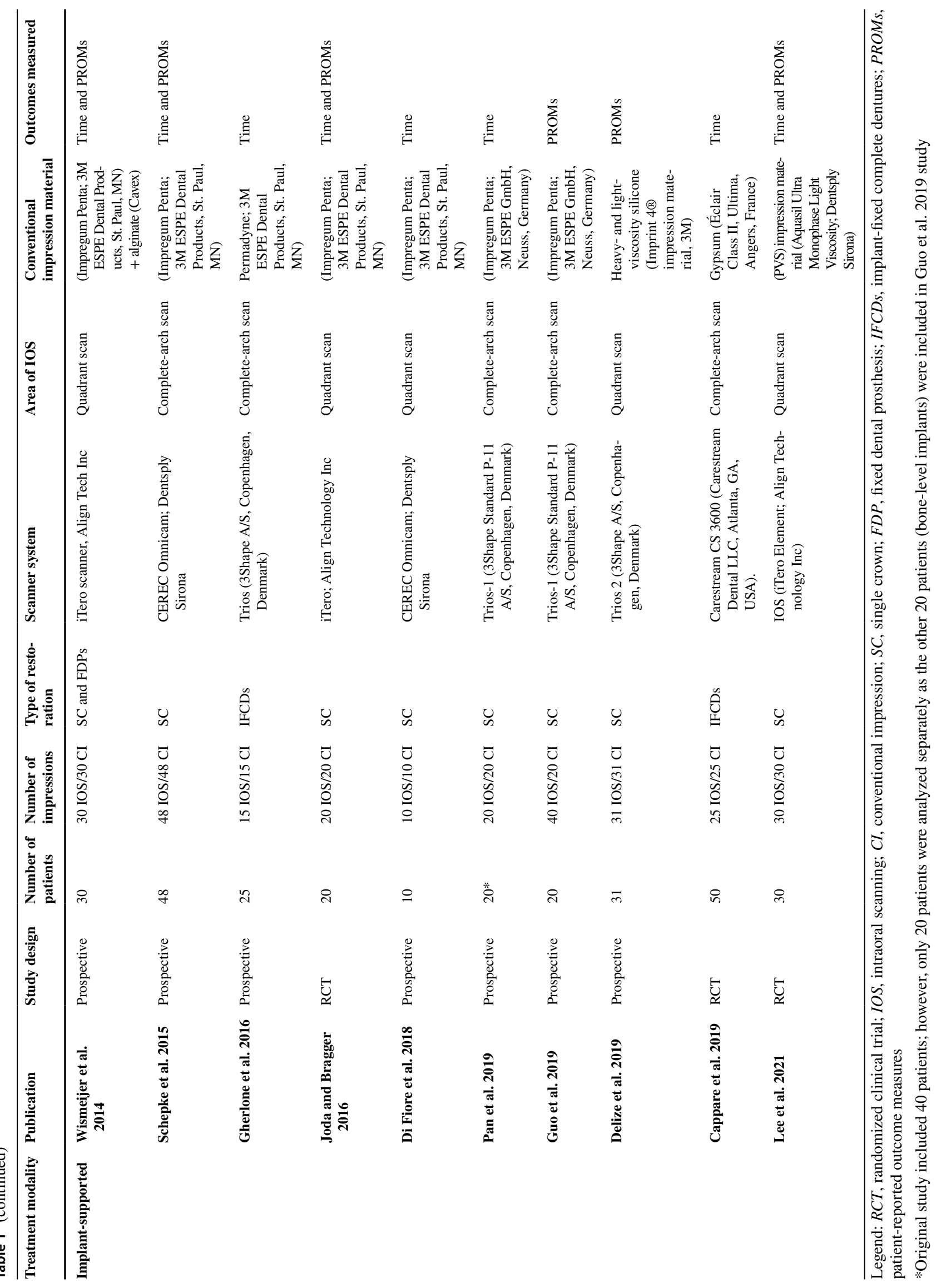


studies. Table 1 details the articles selected for inclusion. Authors of three different studies provided additional information relevant to the inclusion criteria (Supplementary Table 2). Kappa scores were calculated for inter-reviewer reliability, yielding 0.87 for title/abstract screening and 0.97 for full-text evaluation. Any disagreement was solved by discussion and consultation with a third reviewer (Z.C.).

\section{Characteristics of included studies}

Nine of the included studies were RCTs [10-12, 14, 16, 28, $33,35,36]$, and eight were prospective clinical studies [9, $13,15,29,37-40]$.

Seven studies evaluated time efficiency and/or PROMs of impression procedures for tooth-supported restorations $[10,12,14,28,33,35,39]$, with four of these studies conducting quadrant scans [12, 28, 33, 39], two performing complete arch scans [10,14], and one including both quadrant and complete-arch scans conducted for single crowns and 3-unit FDPs (fixed dental prosthesis), respectively [35]. The remaining ten studies reported outcomes for working time and/or PROMs of impression procedures for implantsupported restorations $[9,11,13,15,16,29,36-38,40]$, with five of the studies conducting quadrant scans [11, 15, $16,29,37]$ and the remaining five performing complete-arch scans $[9,36,38,40]$.

Eleven studies reported exclusively on impression procedures for single crown restorations $[9,11-13,15,16,28$, $29,33,38,39]$, while three studies reported outcomes for impression procedures conducted in preparation for both single crowns and FDPs [10, 35, 37]. One study reported exclusively on impression procedures for FDPs [14], and two studies reported outcomes for complete-arch implantsupported restorations [36, 40]. The 17 included studies provided data from 430 IOS and 370 conventional impressions performed in 437 patients. A total of 7 different IOS systems and their various updated versions were used for digital impressions: (a) Trios (7/17 included studies); (b) iTero (5/17); (c) Lava (3/17); (d) Omnicam (2/17); (e) Bluecam (2/17); (f) 3 M True Definition (1/17); and (g) Carestream (1/17) (Table 1). Multiple IOS systems were used in the same trial for two different studies [14, 33]. For conventional impressions, polyether (10/17) and PVS (6/17) materials were used. Gypsum (Éclair Class II, Ultima, Angers, France) was used in the Cappare 2019 study (1/16).

\section{Study outcomes}

\section{Time efficiency}

The quantitative analysis comprised of 14 studies demonstrated that IOS was overall faster than conventional impressions (Table 2). The mean time for impression procedures was calculated for digital and conventional impressions, subdivided based on whether impressions were conducted for implant-supported or tooth-supported restorative workflows. Digital impressions were also subdivided based on the size of the scanned area (quadrant or complete-arch scans). For implant-supported restorations, the mean working time for impression procedures was higher for conventional impressions compared to digital $(16.74 \pm 5.24$ vs. $12.06 \pm 4.52 \mathrm{~min}$, respectively). The same trend was seen when comparing conventional and digital impressions for tooth-supported restorations $(13.94 \pm 5.35$ vs. $11.57 \pm 5.8 \mathrm{~min}$, respectively). For IOS, no clear trend was seen regarding the influence of the size of the scanned area on working time; for implant-supported restorations, complete-arch scanning exhibited a shorter working time than quadrant scanning, but for tooth-supported restorations, the opposite was true. For mean retake time, implant-supported restorations prepared from quadrant $(2.57 \pm 0.42 \mathrm{~min})$ or complete-arch IOS $(1.80 \pm 1.08 \mathrm{~min})$ were associated with shorter retake times

Table 2 Mean working time, retake time, and number of retakes for digital and conventional impression procedures

\begin{tabular}{|c|c|c|c|c|c|c|}
\hline & \multicolumn{4}{|l|}{ Digital } & \multicolumn{2}{|l|}{ Conventional } \\
\hline & Implant quadrant & Implant full arch & Tooth quadrant & Tooth full arch & Implant & Tooth \\
\hline \multirow[t]{2}{*}{$\begin{array}{l}\text { Mean time for } \\
\text { impression (min) }\end{array}$} & $\begin{array}{l}15.55 \pm 3.49(n \\
=4)\end{array}$ & $\begin{array}{l}8.62 \pm 1.79(n \\
\quad=4)\end{array}$ & $\begin{array}{l}7.74 \pm 2.32(n \\
=4)\end{array}$ & $\begin{array}{l}16.19 \pm 5.35(n \\
\quad=3)\end{array}$ & $\begin{array}{l}16.74 \pm 5.24(n \\
\quad=8)\end{array}$ & $\begin{array}{l}13.94 \pm 5.35(n \\
=7)\end{array}$ \\
\hline & \multicolumn{2}{|c|}{$\begin{array}{l}\text { Total for implant IOS: } 12.06 \pm 4.52 \\
(n=8)\end{array}$} & \multicolumn{2}{|c|}{$\begin{array}{l}\text { Total for tooth IOS: } 11.57 \pm 5.8(n \\
\quad=7)\end{array}$} & & \\
\hline $\begin{array}{l}\text { Mean retake time } \\
(\min )\end{array}$ & $\begin{array}{l}2.57 \pm 0.42(n \\
=2)\end{array}$ & $\begin{array}{l}1.80 \pm 1.08(n \\
=2)\end{array}$ & $\mathrm{n} / \mathrm{a}$ & $\mathrm{n} / \mathrm{a}$ & $\begin{array}{l}3.65 \pm 2.57(n \\
\quad=4)\end{array}$ & $2.63(n=1)$ \\
\hline Mean retake no. & $0.17(n=1)$ & $\begin{array}{l}8.00 \pm 1.41(n \\
\quad=2)\end{array}$ & $\begin{array}{l}2.33 \pm 1.52(n \\
=1)\end{array}$ & $\begin{array}{l}3.33 \pm 3.51(n \\
\quad=1)\end{array}$ & $\begin{array}{l}1.72 \pm 1.43(n \\
=3)\end{array}$ & $1.66 \pm 1.15(n=3)$ \\
\hline
\end{tabular}

$S D$, standard deviation of the mean;

$n$, number of studies reporting this outcome;

$n / a$, not available 
Fig. 2 Time efficiency of impression procedures reported in included studies
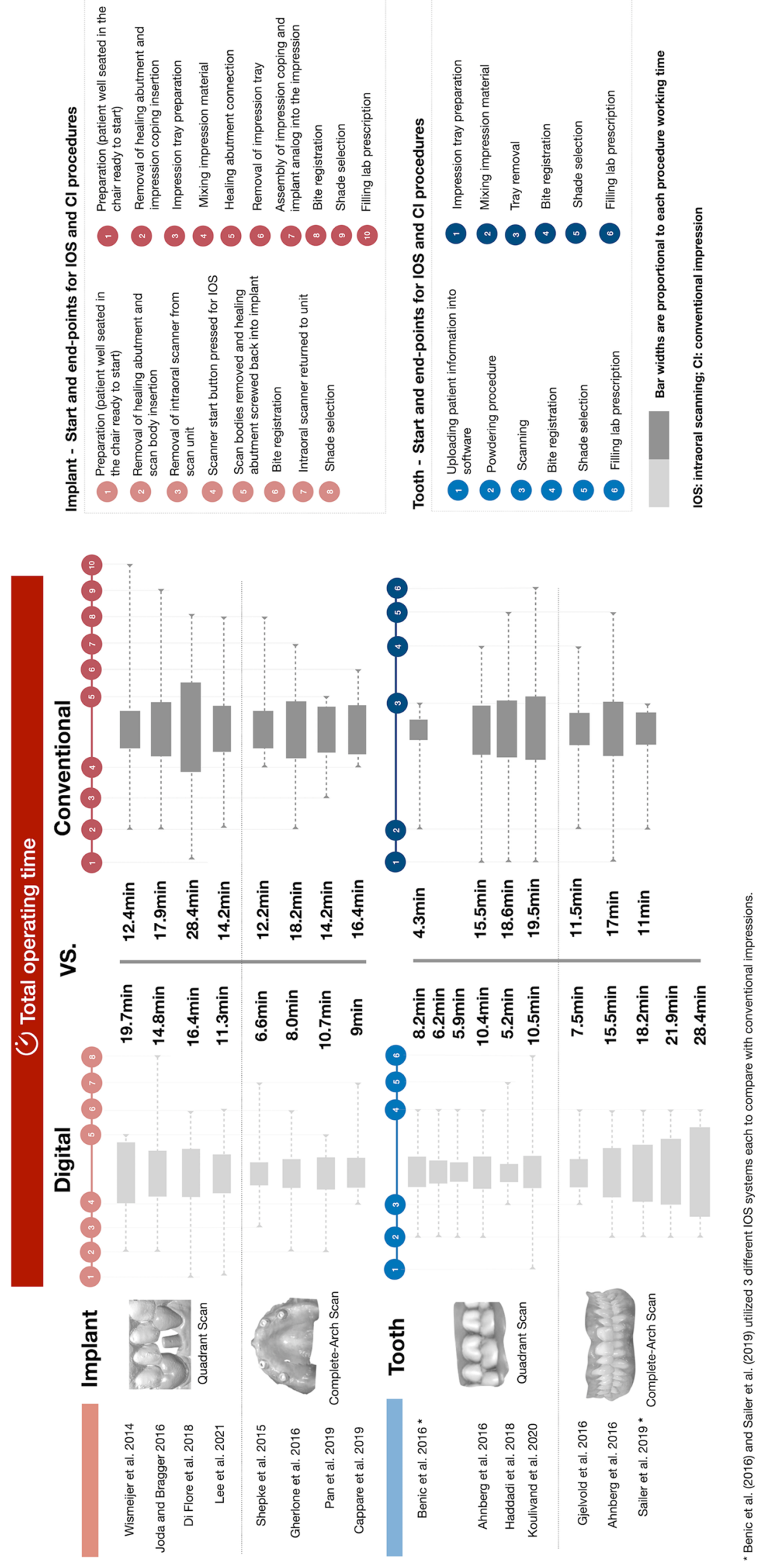


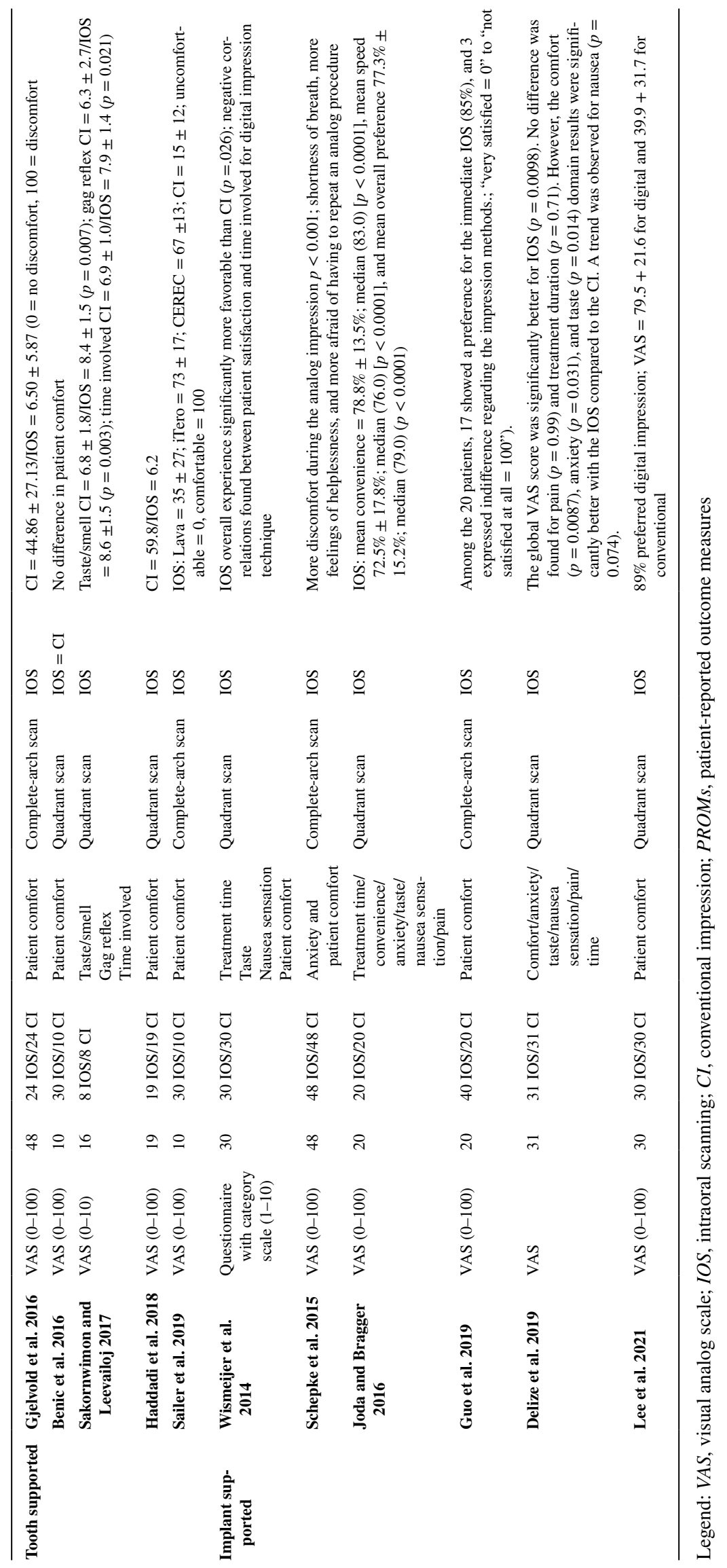


compared to conventional impressions $(3.65 \pm 2.57 \mathrm{~min})$. No data was available for retake time associated with toothsupported restorations prepared from IOS. Regarding mean retake number, a clear trend was seen where IOS was generally associated with higher retake numbers for both toothand implant-supported restorations in comparison with conventional impressions.

Qualitative analysis of the working time associated with impression procedures for each of the included studies, including start and end points, is illustrated in Fig. 2. The procedure working times for IOS and conventional impressions ranged from 5.2 to $28.4 \mathrm{~min}$ and 4.3 to $28.4 \mathrm{~min}$, respectively. Overall, 11/14 studies reported that IOS was faster than conventional impressions [9-12, 15, 16, 35, 36, $38-40]$. Only three studies $[14,33,37]$ reported that conventional impressions were associated with a reduced working time when compared to digital impressions. One of these studies compared quadrant scans of tooth preparations to conventional impressions [33]. Another study compared quadrant scans to conventional impressions for implant restorations [37], and Sailer et al. compared complete arch scans to conventional impressions for 3-unit tooth-supported FDPs [14]. In regards to tooth-supported restorations, two studies found that quadrant scans were faster than conventional impressions [12,39], and one study reported that complete arch scans [10] were faster. Ahrberg et al. reported that both quadrant and complete-arch scans were faster than conventional impressions [35] (Fig. 2). Out of the studies involving implant-supported restorations, three reported that quadrant scans were faster than conventional impressions $[11,15,16]$, while four studies reported reduced procedure times for complete arch scans relative to conventional impressions [9, 36, 38, 40]. The results demonstrated that IOS was overall faster than conventional impressions independent of whether quadrant or complete arch scanning was utilized, regardless of the nature of the restoration (tooth- or implant-supported).

\section{Patient-reported outcomes (PROMs)}

Data from the 11 included studies reporting on PROMs revealed an overall patient preference for digital compared to conventional impressions (Table 3). While one study [33] showed no difference in patient comfort comparing conventional and digital impressions, the remaining 10 studies [9-14, 16, 28, 29, 37] reported a patient preference for digital impressions. The most frequently reported parameters favoring digital impressions were: negatively perceived taste resulting from analog impressions [28, 29, 37], shortness of breath and activation of the gag reflex $[9,28]$, anxiety [9, 29], the preparatory activities involved [37], fear of having to repeat analog impressions [9], and overall comfort $[14-16,29]$. The results suggest that IOS was generally preferred over conventional impressions regardless of the size of the scanned area and nature of the restoration (toothor implant-supported).

\section{Prosthodontics outcomes}

Quantitative data regarding the quality of prosthodontic outcomes were available in seven of the included studies based on indirect assessment during crown delivery and direct assessment of crown fit. Two studies [16, 29] demonstrated comparable success rates between digital and conventional workflows for single-implant crown restorations and similar outcomes for occlusal and interproximal contacts. Another study [38] found no difference in clinical chairside time during crown delivery between workflows using digital (25.7 $\mathrm{min}$ ) or conventional (23.2 $\mathrm{min}$ ) impressions, as well as similar numbers of crowns that could not be delivered due to poor fit between digital (six crowns) and conventional (five crowns) groups. In addition, a total of 12 crowns from the conventional group required no chairside adjustment during delivery compared to four in the digital group, and 15 conventional crowns required proximal adjustments compared to 28 digital crowns [38]. In the study by Lee and coworkers of the crowns chosen for delivery, $46.7 \%$ were from conventional impressions and 53.3\% from digital scans [16]. A different trial [10] reported similar marginal fit and interproximal contact points for single crowns and FDPs fabricated from digital and conventional impressions, whereas better results were observed for occlusal contacts in the digital group. Direct assessment of the internal gap and the marginal fit demonstrated superior results for digital (49.4 and $60.1 \mu \mathrm{m}$, respectively) compared to conventional (91.9 and $97.0 \mu \mathrm{m}$, respectively) impression techniques resulting in less frequent adjustments prior to delivery of digital crowns [39]. Ahrberg and coworkers reported better marginal fit and internal fit at the occlusal region for digital (61.1 and $155.6 \mu \mathrm{m}$, respectively) compared to conventional (70.4 and $171.5 \mu \mathrm{m}$, respectively) crowns [35]. Sakornwimon and Leevailoj reported a lower number of crowns requiring interproximal and occlusal adjustments for digital (eight and five, respectively) compared to conventional (12 and 12, respectively) techniques [28]. Similar marginal discrepancies were found at buccal, mesial, lingual, and distal sites ranging from 42.6 to $76.6 \mu \mathrm{m}$ for digital and 39.0 to $71.7 \mu \mathrm{m}$ for conventional crowns. Overall, the majority of studies reported similar prosthodontic outcomes for workflows implementing conventional and digital impression techniques.

\section{Quality of the studies}

The risk of bias for the nine included RCTs is evaluated and summarized in Table 4. One study [28] presented a high risk 
Table 4 Risk of bias assessment for included RCTs according to the Cochrane guidelines

\begin{tabular}{|c|c|c|c|c|c|c|c|}
\hline Study & $\begin{array}{l}\text { Random } \\
\text { sequence gen- } \\
\text { eration }\end{array}$ & $\begin{array}{l}\text { Allocation } \\
\text { concealment }\end{array}$ & $\begin{array}{l}\text { Blinding of partici- } \\
\text { pants and personnel }\end{array}$ & $\begin{array}{l}\text { Blinding of out- } \\
\text { come assessment }\end{array}$ & $\begin{array}{l}\text { Incomplete } \\
\text { outcome data }\end{array}$ & $\begin{array}{l}\text { Selective } \\
\text { reporting }\end{array}$ & Other bias \\
\hline Gjevold et al 2016 & Low & Unclear & High & High & Low & Low & Low \\
\hline Benic et al 2016 & Low & Unclear & High & High & Low & Low & Low \\
\hline Joda and Bragger 2016 & Low & Unclear & High & High & Low & Low & Low \\
\hline Sakorniwon et al 2017 & High & High & High & High & Low & High & Low \\
\hline Haddadi et al 2018 & Unclear & Unclear & High & High & Low & Low & Low \\
\hline Sailer et al 2019 & Low & Low & High & High & Low & Low & Low \\
\hline Ahnberg et al 2016 & Low & Unclear & High & High & Low & Low & Low \\
\hline Cappare et al. 2019 & Low & Low & High & High & Low & Low & Low \\
\hline Lee et al. 2021 & Low & Low & High & High & Low & Low & Low \\
\hline
\end{tabular}

of nonrandom sequence generation, and one [12] was associated with an unclear risk. Regarding allocation concealment, one study [28] was found to have a high risk of bias, and five studies [10-12, 35, 41] had an unclear risk. For the blinding of participants and personnel and the blinding of outcome assessment, all of the included studies were associated with a high risk of bias as a result of informed operators. As for incomplete outcome data, selective reporting, and other sources of bias, all of the included studies were associated with a low risk of bias.

The risk of bias for the eight included non-RCTs is summarized in Table 5. Among the included non-RCTs, there was one article which attained seven stars [37] denoting a high standard of quality. The remaining seven articles $[9,13$,
15, 29, 38-40] attained 4-6 stars, representing moderatequality evidence.

\section{Discussion}

The present systematic review evaluated the literature concerning the current evidence available on time efficiency and PROMs in order to compare IOS to conventional impressions. To the best of our knowledge, this is the first systematic review comparing time efficiency and PROMs taking the variable of the size of the scanned area into consideration (sectional vs. complete arch). In addition, the present systematic review is the first in the literature to analyze mean

Table 5 Risk of bias assessment for included non-RCTs according to the Newcastle-Ottawa Scale

\begin{tabular}{|c|c|c|c|c|c|c|c|c|c|}
\hline Study & $\begin{array}{l}\text { Representa- } \\
\text { tiveness of } \\
\text { the exposed } \\
\text { cohort }\end{array}$ & $\begin{array}{l}\text { Selection of } \\
\text { the nonex- } \\
\text { posed cohort }\end{array}$ & $\begin{array}{l}\text { Ascertain- } \\
\text { ment of } \\
\text { exposure }\end{array}$ & $\begin{array}{l}\text { Outcome of } \\
\text { interest not } \\
\text { present at the } \\
\text { start of the } \\
\text { study }\end{array}$ & $\begin{array}{l}\text { Comparability } \\
\text { of cohorts on } \\
\text { the basis of } \\
\text { the design or } \\
\text { analysis }\end{array}$ & $\begin{array}{l}\text { Assessment } \\
\text { of outcome }\end{array}$ & $\begin{array}{l}\text { Sufficient } \\
\text { follow-up for } \\
\text { the outcome } \\
\text { to occur }\end{array}$ & $\begin{array}{l}\text { Adequacy } \\
\text { of follow- } \\
\text { up }\end{array}$ & Total \\
\hline $\begin{array}{l}\text { Wismeijer } \\
\text { et al. } 2014\end{array}$ & $\star$ & $\star$ & $\star$ & $\star$ & $\star$ & 㶦 & $\star$ & $\star$ & 7 \\
\hline $\begin{array}{l}\text { Schepke et al. } \\
2015\end{array}$ & 㶦 & $\star$ & $\star$ & $\star$ & $\star$ & 头 & $\star$ & $\star$ & 6 \\
\hline $\begin{array}{l}\text { Delize et al. } \\
2019\end{array}$ & 㶦 & $\star$ & $\star$ & $\star$ & $\star$ & 幽 & $\star$ & $\star$ & 6 \\
\hline $\begin{array}{l}\text { Pan et al. } \\
2019\end{array}$ & 为 & $\star$ & $\star$ & $\star$ & $\star$ & 㶦 & $\star$ & $\star$ & 6 \\
\hline $\begin{array}{l}\text { Guo et al. } \\
2019\end{array}$ & 㶦 & $\star$ & $\star$ & $\star$ & $\star$ & 匀 & $\star$ & $\star$ & 6 \\
\hline $\begin{array}{l}\text { Koulivand } \\
\text { et al. } 2020\end{array}$ & is & $\star$ & $\star$ & $\star$ & $\star$ & 访 & $\star$ & $\star$ & 6 \\
\hline $\begin{array}{l}\text { Di Fiore et al. } \\
2018\end{array}$ & 㶦 & $\star$ & $\star$ & $\star$ & $\star$ & 头 & $\star$ & $\star$ & 6 \\
\hline $\begin{array}{l}\text { Gherlone } \\
\text { et al. } 2016\end{array}$ & 㶦 & $\star$ & $\star$ & $\star$ & 㶦 & 头 & $\star$ & $\star$ & 5 \\
\hline
\end{tabular}


working time for impression procedures, mean retake time, and mean retake number in order to allow comparisons between digital and conventional impressions subdivided based on the size of the scanned area and association with either implant- or tooth-supported restorations. Prosthodontic outcomes, such as crown fit and occlusal/interproximal contacts were also compared between workflows utilizing conventional and digital impressions, when available. Overall, the results demonstrated that IOS was generally faster and preferred by patients with comparable prosthodontic outcomes to conventional impressions.

The favorable PROMs associated with IOS are linked to avoidance of common issues experienced by patients during conventional impressions. Interestingly, the only study showing no difference in patient comfort between IOS and the conventional impression was also one of few studies where conventional impressions were faster than digital [41], suggesting that procedure working time is an important variable influencing the patient experience. Interestingly, Delize and coworkers reported better scores for the patient perception of conventional compared to digital crowns [29]. This finding can be explained by the selection of restoration with superior esthetics (multilayered veneered zirconia) for the conventional approach compared to monolithic zirconia for the digital group.

Regarding time efficiency, a level of variability between the different studies was noted; however, a clear trend for a reduced working time was seen for IOS compared to conventional impressions. IOS was also associated with a lower mean retake time but a higher mean retake number. A possible explanation for this result is that clinicians were more likely to take advantage of the ability to rescan a missed area when using digital impression techniques. In comparison, retaking a conventional impression would mean having to redo the whole procedure. Many different variables, including the type of IOS system utilized [42, 43], operator experience and comfort level, as well the start and end points chosen for measuring procedure working time can have a potential impact on time efficiency outcomes. Sailer et al. 2019 utilized a first-generation IOS system (Bluecam; Dentsply Sirona) requiring powder application (a step not required with newer models) and reported a relatively high mean procedure working time of $28.4 \mathrm{~min}$ for digital impressions [14]. A trend toward longer working times for older IOS systems was demonstrated in some of the earlier clinical studies $[11,37]$. In addition, the specific type of conventional impression technique utilized needs to be considered in comparison with digital impressions. Benic et al. (2016) used a closed-mouth conventional impression technique, which allowed impressions of both jaws and occlusal registration in a single step [41]. This is a possible reason why the conventional impression procedure was faster than IOS in this specific trial.
A great advantage of IOS compared to conventional impressions is the ability to rescan missed areas and to previsualize areas allowing feedback in real time. For conventional impressions, an error is often only detectable after the complete setting of the impression material or pouring a stone cast. While rescanning to "repair" a certain aspect of the scan that is inadequate can be beneficial, it is important to note that avoiding the need for this additional step with an optimal scanning strategy can reduce the overall procedure working time.

The level of operator experience was previously demonstrated to play an important role in IOS working time [44, 45]. Resende and his colleagues showed that less experienced operators required significantly longer times for IOS when compared with moderately and highly experienced operators [45]. However, the difference in time was within $70 \mathrm{~s}$, and thus is likely not clinically relevant. In the present review, four out of the 14 studies reporting working time did not clearly describe the level of operator experience in regard to IOS $[12,15,38,40]$. Intriguingly, all four of these studies reported IOS being faster than conventional impressions. All the remaining studies described the operators as experienced or receiving adequate training and calibration before the clinical procedures.

Numerous studies have evaluated and compared prosthodontic treatment outcomes after conventional or digital impressions. A meta-analysis demonstrated similar marginal discrepancies between digital and conventional crowns [46] and long-term clinical studies revealed favorable survival rates of $92.5 \%, 85.5 \%$, and $81.9 \%$ after 5,10 , and 15 years [47]. However, the data analysis from the included clinical studies investigating PROMs and prosthodontic outcomes were not available. Among the 17 studies included in the current systematic review, a total of seven studies reported data for prosthodontic outcomes. Overall, similar success rates were found for both digital and conventional workflows regarding restorative fit, interproximal contacts, and occlusion [29]. Digital crowns also required fewer adjustments and time during crown delivery $[28,39]$.

The present study is not exempt from limitations. The main limitation of the present review is the different study designs among the included studies, and heterogeneity in how procedural time and PROMs were measured. Another limitation is the lack of participant and operator blinding that can influence patient responses and treatment outcomes. However, as the two treatment methods are easily differentiable, it will never be possible to perform without the knowledge of the patient and operator.

\section{Clinical implications}

Prosthodontic patients have often suffered extensive loss of tooth structure and/or tooth loss, as a result of periodontal 
disease, caries, and dental trauma. Edentulism is associated with a decreased quality of life due to the importance of dentition in esthetics, mastication, and speech [48]. PROMs are defined as an instrument comprised of a set of questions that reflect the patient's perception of their functional well-being and health status before and after treatment [49]. It is highly desirable that dental interventions are able to address common complaints from patients in order to increase patient satisfaction and acceptance toward treatment. Therefore, evaluating the time efficiency and PROMs of a new clinical approach such as IOS is of paramount importance.

Another important clinical benefit, especially in the context of the current COVID-19 pandemic, is that a digital prosthetic workflow can possibly help in terms of reducing the risk of disease transmission [50]. Biologic fluids (saliva and blood) present in conventional impressions require disinfection, a step which can promote impression material distortion [51]. Also, the need for physical delivery to a dental laboratory and storage can also serve as a source of contamination between operators [52, 53]. Moreover, with the serious negative financial implications to dental practices imposed by the COVID-19 pandemic [54, 55], the financial cost is an important consideration. A recently published study showed that digital impressions are more efficient and cost-effective than standard impressions, and implementation costs can be offset within the first year of dental practice [56]. However, IOS is not free of limitations. A recently published controlled trial showed that deep preparation of the prosthetic margin into the sulcus is not recommended for IOS as it leads to greater inaccuracies in the digital impression [57].

\section{Future research implications}

There are no specific guidelines regarding how procedural working time and PROMS should be assessed during prosthetic treatment in order to guide future clinical practice and research. Different clinical settings, conventional impression techniques, and materials, as well as heterogeneity in IOS systems and strategies utilized, are some of the major challenges encountered when comparing time effectiveness between digital and conventional impressions. Adequate calibration of operators and detailed information about each procedural step and time point evaluated are crucial in order to minimize methodological heterogeneity and to allow for a precise comparison between articles. Currently, researchers and clinicians interested in evaluating PROMs often utilize a set of non-standardized questions that are administered through questionnaires or personal interviews. As discussed in an article by Reissmann, in the future, PROMs should be further developed into a standardized tool to assess patient perceptions before and after treatment [27]. Increased standardization in the way PROMs are measured in the literature will facilitate the ability of future studies to conduct quantitative comparisons of treatment effects.

\section{Conclusion}

Based on the currently available evidence and within the limitations of this review, the following conclusions can be drawn.

(1) IOS is faster than conventional impressions, independent of the size of the scanned area (regardless of whether a quadrant or complete-arch scan is conducted).

(2) IOS can improve the patient experience in the dental office measured by overall preference and comfort.

(3) IOS as part of a digital workflow is able to provide reliable prosthodontic outcomes.

Supplementary Information The online version contains supplementary material available at https://doi.org/10.1007/s00784-021-04157-3.

\section{Declarations}

Ethics approval This article does not contain any studies with human participants or animals performed by any of the authors.

Informed consent For this type of study, formal consent is not required.

Conflict of interest The authors declare no competing interests.

\section{References}

1. Pant R, Juszczyk AS, Clark RK, Radford DR (2008) Long-term dimensional stability and reproduction of surface detail of four polyvinyl siloxane duplicating materials. J Dent 36:456-461. https://doi.org/10.1016/j.jdent.2008.03.003

2. Donovan TE, Chee WW (2004) A review of contemporary impression materials and techniques. Dent Clin North Am 48:vivii 445-70. https://doi.org/10.1016/j.cden.2003.12.014

3. Chee WW, Donovan TE (1992) Polyvinyl siloxane impression materials: a review of properties and techniques. J Prosthet Dent 68:728-732. https://doi.org/10.1016/0022-3913(92)90192-d

4. Tsirogiannis P, Neophytou S, Reul A, Heydecke G, Reissmann DR (2017) Can we measure patients' perception during dental impressions? The Burdens in Dental Impression-Making Questionnaire - BiDIM-Q. J Prosthodont Res 61:34-42. https://doi.org/ 10.1016/j.jpor.2016.03.003

5. Hacker T, Heydecke G, Reissmann DR (2015) Impact of procedures during prosthodontic treatment on patients' perceived burdens. J Dent 43:51-57. https://doi.org/10.1016/j.jdent.2014. 10.013

6. Conny DJ, Tedesco LA, Brewer JD, Albino JE (1985) Changes of attitude in fixed prosthodontic patients. J Prosthet Dent 53:451454. https://doi.org/10.1016/0022-3913(85)90623-7

7. Schropp L, Wenzel A, Kostopoulos L, Karring T (2003) Bone healing and soft tissue contour changes following single-tooth 
extraction: a clinical and radiographic 12 -month prospective study. Int J Periodontics Restorative Dent 23:313-323

8. Lee SJ, Gallucci GO (2013) Digital vs. conventional implant impressions: efficiency outcomes. Clin Oral Implants Res 24:111115. https://doi.org/10.1111/j.1600-0501.2012.02430.x

9. Schepke U, Meijer HJ, Kerdijk W, Cune MS (2015) Digital versus analog complete-arch impressions for single-unit premolar implant crowns: operating time and patient preference. J Prosthet Dent 114:403-6.e1. https://doi.org/10.1016/j.prosdent.2015.04. 003

10. Gjelvold B, Chrcanovic BR, Korduner EK, Collin-Bagewitz I, Kisch J (2016) Intraoral digital impression technique compared to conventional impression technique. A randomized clinical trial J Prosthodont 25:282-287. https://doi.org/10.1111/jopr.12410

11. Joda T, Bragger U (2016) Patient-centered outcomes comparing digital and conventional implant impression procedures: a randomized crossover trial. Clin Oral Implants Res 27:e185-e189. https://doi.org/10.1111/clr.12600

12. Haddadi Y, Bahrami G, Isidor F (2018) Evaluation of operating time and patient perception using conventional impression taking and intraoral scanning for crown manufacture: a split-mouth, randomized clinical study. Int J Prosthodont 31:55-59. https://doi. org/10.11607/ijp.5405

13. Guo DN, Liu YS, Pan SX, Wang PF, Wang B, Liu JZ, Gao WH, Zhou YS (2019) Clinical efficiency and patient preference of immediate digital impression after implant placement for single implant-supported crown. Chin J Dent Res 22:21-28. https://doi. org/10.3290/j.cjdr.a41771

14. Sailer I, Muhlemann S, Fehmer V, Hammerle CHF, Benic GI (2019) Randomized controlled clinical trial of digital and conventional workflows for the fabrication of zirconia-ceramic fixed partial dentures. Part I: time efficiency of complete-arch digital scans versus conventional impressions. J Prosthet Dent 121:6975. https://doi.org/10.1016/j.prosdent.2018.04.021

15. Di Fiore A, Vigolo P, Graiff L, Stellini E (2018) Digital vs Conventional workflow for screw-retained single-implant crowns: a comparison of key considerations. Int J Prosthodont 31:577-579. https://doi.org/10.11607/ijp.5938

16. Lee SJ, Jamjoom FZ, Le T, Radics A, Gallucci GO (2021) A clinical study comparing digital scanning and conventional impression making for implant-supported prostheses: a crossover clinical trial. J Prosthet Dent. https://doi.org/10.1016/j.prosdent.2020.12. 043

17. Marghalani A, Weber HP, Finkelman M, Kudara Y, El Rafie K, Papaspyridakos P (2018) Digital versus conventional implant impressions for partially edentulous arches: an evaluation of accuracy. J Prosthet Dent 119:574-579. https://doi.org/10.1016/j.prosd ent.2017.07.002

18. Muhlemann S, Benic GI, Fehmer V, Hammerle CHF, Sailer I (2019) Randomized controlled clinical trial of digital and conventional workflows for the fabrication of zirconia-ceramic posterior fixed partial dentures. Part II: time efficiency of CAD-CAM versus conventional laboratory procedures. J Prosthet Dent 121:252257. https://doi.org/10.1016/j.prosdent.2018.04.020

19. Joda T, Bragger U, Zitzmann NU (2019) CAD/CAM implant crowns in a digital workflow: five-year follow-up of a prospective clinical trial. Clin Implant Dent Relat Res 21:169-174. https://doi. org/10.1111/cid.12681

20. Joda T, Bragger U (2015) Time-efficiency analysis comparing digital and conventional workflows for implant crowns: a prospective clinical crossover trial. Int J Oral Maxillofac Implants 30:1047-53. https://doi.org/10.11607/jomi.3963

21. Ender A, Zimmermann M, Attin T, Mehl A (2016) In vivo precision of conventional and digital methods for obtaining quadrant dental impressions. Clin Oral Investig 20:1495-1504. https://doi. org/10.1007/s00784-015-1641-y
22. Abduo J, Elseyoufi M (2018) Accuracy of intraoral scanners: a systematic review of influencing factors. Eur J Prosthodont Restor Dent 26:101-121. https://doi.org/10.1922/EJPRD_01752Abduo21

23. Revilla-Leon M, Subramanian SG, Ozcan M, Krishnamurthy VR (2020) Clinical study of the influence of ambient light scanning conditions on the accuracy (trueness and precision) of an intraoral scanner. J Prosthodont 29:107-113. https://doi.org/10.1111/jopr. 13135

24. Kim J, Park JM, Kim M, Heo SJ, Shin IH, Kim M (2016) Comparison of experience curves between two 3-dimensional intraoral scanners. J Prosthet Dent 116:221-230. https://doi.org/10.1016/j. prosdent.2015.12.018

25. Li H, Lyu P, Wang Y, Sun Y (2017) Influence of object translucency on the scanning accuracy of a powder-free intraoral scanner: a laboratory study. J Prosthet Dent 117:93-101. https://doi. org/10.1016/j.prosdent.2016.04.008

26. Zimmermann M, Mehl A, Mormann WH, Reich S (2015) Intraoral scanning systems - a current overview. Int J Comput Dent 18:101-129

27. Reissmann DR (2019) Dental patient-reported outcome measures are essential for evidence-based prosthetic dentistry. J Evid Based Dent Pract 19:1-6. https://doi.org/10.1016/j.jebdp.2019.01.003

28. Sakornwimon N, Leevailoj C (2017) Clinical marginal fit of zirconia crowns and patients' preferences for impression techniques using intraoral digital scanner versus polyvinyl siloxane material. J Prosthet Dent 118:386-391. https://doi.org/10.1016/j.prosdent. 2016.10.019

29. Delize V, Bouhy A, Lambert F, Lamy M (2019) Intrasubject comparison of digital vs. conventional workflow for screw-retained single-implant crowns: prosthodontic and patient-centered outcomes. Clin Oral Implants Res 30:892-902. https://doi.org/10. 1111/clr.13494

30. Gallardo YR, Bohner L, Tortamano P, Pigozzo MN, Lagana DC, Sesma N (2018) Patient outcomes and procedure working time for digital versus conventional impressions: a systematic review. J Prosthet Dent 119:214-219. https://doi.org/10.1016/j.prosdent. 2017.07.007

31. Higgins JP, Altman DG, Gotzsche PC, Juni P, Moher D, Oxman AD, Savovic J, Schulz KF, Weeks L, Sterne JA, Cochrane Bias Methods Group and Cochrane Statistical Methods Group (2011) The Cochrane Collaboration's tool for assessing risk of bias in randomised trials. BMJ 343:d5928. https://doi.org/10.1136/bmj. d5928

32. Stone PW (2002) Popping the (PICO) question in research and evidence-based practice. Appl Nurs Res 15:197-198. https://doi. org/10.1053/apnr.2002.34181

33. Benic GI, Mühlemann S, Fehmer V, Hämmerle CH, Sailer I (2016) Randomized controlled within-subject evaluation of digital and conventional workflows for the fabrication of lithium disilicate single crowns. Part I: digital versus conventional unilateral impressions. J Prosthet Dent 116:777-782. https://doi.org/10. 1016/j.prosdent.2016.05.007

34. Stang A (2010) Critical evaluation of the Newcastle-Ottawa Scale for the assessment of the quality of nonrandomized studies in meta-analyses. Eur J Epidemiol 25:603-605. https://doi.org/10. 1007/s10654-010-9491-z

35. Ahrberg D, Lauer HC, Ahrberg M, Weigl P (2016) Evaluation of fit and efficiency of CAD/CAM fabricated all-ceramic restorations based on direct and indirect digitalization: a double-blinded, randomized clinical trial. Clin Oral Investig 20:291-300. https:// doi.org/10.1007/s00784-015-1504-6

36. Cappare P, Sannino G, Minoli M, Montemezzi P, Ferrini F (2019) Conventional versus digital impressions for full arch screwretained maxillary rehabilitations: a randomized clinical trial. Int J Environ Res Public Health 16(5):829. https://doi.org/10.3390/ ijerph16050829 
37. Wismeijer D, Mans R, van Genuchten M, Reijers HA (2014) Patients' preferences when comparing analogue implant impressions using a polyether impression material versus digital impressions (Intraoral Scan) of dental implants. Clin Oral Implants Res 25:1113-1118. https://doi.org/10.1111/clr.12234

38. Pan S, Guo D, Zhou Y, Jung RE, Hammerle CHF, Muhlemann S (2019) Time efficiency and quality of outcomes in a modelfree digital workflow using digital impression immediately after implant placement: a double-blind self-controlled clinical trial. Clin Oral Implants Res 30:617-626. https://doi.org/10.1111/clr. 13447

39. Koulivand S, Ghodsi S, Siadat H, Alikhasi M (2020) A clinical comparison of digital and conventional impression techniques regarding finish line locations and impression time. J Esthet Restor Dent 32:236-243. https://doi.org/10.1111/jerd.12527

40. Gherlone E, Cappare P, Vinci R, Ferrini F, Gastaldi G, Crespi R (2016) Conventional versus digital impressions for "All-on-Four" restorations. Int J Oral Maxillofac Implants 31:324-30. https://doi. org/10.11607/jomi.3900

41. Benic GI, Muhlemann S, Fehmer V, Hammerle CH, Sailer I (2016) Randomized controlled within-subject evaluation of digital and conventional workflows for the fabrication of lithium disilicate single crowns. Part I: digital versus conventional unilateral impressions. J Prosthet Dent 116:777-782. https://doi.org/10. 1016/j.prosdent.2016.05.007

42. Ender A, Mehl A (2013) Influence of scanning strategies on the accuracy of digital intraoral scanning systems. Int J Comput Dent $16: 11-21$

43. Haddadi Y, Bahrami G, Isidor F (2018) Effect of software version on the accuracy of an intraoral scanning device. Int J Prosthodont 31:375-376. https://doi.org/10.11607/ijp.5781

44. Gimenez B, Ozcan M, Martinez-Rus F, Pradies G (2014) Accuracy of a digital impression system based on parallel confocal laser technology for implants with consideration of operator experience and implant angulation and depth. Int J Oral Maxillofac Implants 29:853-62. https://doi.org/10.11607/jomi.3343

45. Resende CCD, Barbosa TAQ, Moura GF, Tavares LDN, Rizzante FAP, George FM, Neves FDD, Mendonca G (2020) Influence of operator experience, scanner type, and scan size on 3D scans. J Prosthet Dent. https://doi.org/10.1016/j.prosdent.2019.12.011

46. Chochlidakis KM, Papaspyridakos P, Geminiani A, Chen CJ, Feng IJ, Ercoli C (2016) Digital versus conventional impressions for fixed prosthodontics: a systematic review and meta-analysis. J Prosthet Dent 116:184-190 e12. https://doi.org/10.1016/j.prosd ent.2015.12.017
47. van den Breemer CR, Vinkenborg C, van Pelt H, Edelhoff D, Cune MS (2017) The clinical performance of monolithic lithium disilicate posterior restorations after 5,10 , and 15 years: a retrospective case series. Int J Prosthodont 30:62-65. https://doi.org/10.11607/ ijp. 4997

48. Clark D, Levin L (2019) In the dental implant era, why do we still bother saving teeth? Dent Traumatol 35:368-375. https://doi.org/ 10.1111/edt. 12492

49. Jokstad A (2018) Patient-reported outcomes (PROs) versus patient-reported outcome measures (PROMs)-is there a difference? Clin Exp Dent Res 4:61-62. https://doi.org/10.1002/cre2. 112

50. Papi P, Di Murro B, Penna D, Pompa G (2020) Digital prosthetic workflow during COVID-19 pandemic to limit infection risk in dental practice. Oral Dis. https://doi.org/10.1111/odi.13442

51. Chidambaranathan AS, Balasubramanium M (2019) Comprehensive review and comparison of the disinfection techniques currently available in the literature. J Prosthodont 28:e849-e856. https://doi.org/10.1111/jopr.12597

52. Barenghi L, Barenghi A, Cadeo C, Di Blasio A (2019) Innovation by computer-aided design/computer-aided manufacturing technology: a look at infection prevention in dental settings. Biomed Res Int 2019:6092018. https://doi.org/10.1155/2019/6092018

53. Sofou A, Larsen T, Fiehn NE, Owall B (2002) Contamination level of alginate impressions arriving at a dental laboratory. Clin Oral Investig 6:161-165. https://doi.org/10.1007/s00784-002-0173-4

54. Ferneini EM (2020) The financial impact of COVID-19 on our practice. J Oral Maxillofac Surg 78:1047-1048. https://doi.org/ 10.1016/j.joms.2020.03.045

55. Ali S, Farooq I, Abdelsalam M, AlHumaid J (2020) Current clinical dental practice guidelines and the financial impact of COVID19 on dental care providers. Eur J Dent. https://doi.org/10.1055/s0040-1716307

56. Resnick CM, Doyle M, Calabrese CE, Sanchez K, Padwa BL (2019) Is it cost effective to add an intraoral scanner to an oral and maxillofacial surgery practice? J Oral Maxillofac Surg 77:16871694. https://doi.org/10.1016/j.joms.2019.03.011

57. Ferrari Cagidiaco E, Zarone F, Discepoli N, Joda T, Ferrari M (2021) Analysis of the reproducibility of subgingival vertical margins using intraoral optical scanning (IOS): a randomized controlled pilot trial. J Clin Med 10(5):941. https://doi.org/10. 3390/jcm10050941

Publisher's note Springer Nature remains neutral with regard to jurisdictional claims in published maps and institutional affiliations.

\section{Authors and Affiliations}

\section{Rafael Siqueira ${ }^{1}$ - Matthew Galli ${ }^{1} \cdot$ Zhaozhao Chen $^{1} \cdot$ Gustavo Mendonça ${ }^{2} \cdot$ Luiz Meirelles $^{3} \cdot$ Hom-Lay Wang $^{1}$. Hsun-Liang Chan ${ }^{1}$}

1 Department of Periodontics and Oral Medicine, University of Michigan School of Dentistry, 1011 North University Avenue, Ann Arbor, MI 48109-1078, USA

2 Department of Biological and Material Sciences \& Prosthodontics, University of Michigan School of Dentistry, Ann Arbor, MI, USA
3 Department of Restorative and Prosthetic Dentistry, College of Dentistry, The Ohio State University, Columbus, $\mathrm{OH}$, USA 